\title{
Making meaning through joint activity in Computer-Supported Collaborative Learning (CSCL) settings: The interplay between content-related and activity-related talk
}

\author{
César Coll* y Anna Engel
}

Departamento de Psicología Evolutiva de la Educación. Universitat de Barcelona, Spain

\begin{abstract}
Título: Construir significados en la actividad conjunta en situaciones de aprendizaje colaborativo mediado por ordenador: la articulación del habla relacionada con el contenido y el habla relacionada con la actividad.

Resumen: En la literatura reciente sobre el CSCL que pone el acento en el discurso de los participantes aparece con claridad una dicotomía entre los trabajos que se centran en el habla relacionada con el contenido y los que lo hacen en el habla relacionada con la actividad. Desde el planteamiento adoptado en este trabajo, basado en la noción de influencia educativa, la hipótesis directriz es que ambas formas de habla se presentan estrechamente articuladas en las dinámicas colaborativas y que el habla relacionada con la actividad, lejos de ser irrelevante, es esencial para hacer avanzar la construcción colaborativa de conocimiento. El trabajo examina empíricamente esta hipótesis en cuatro situaciones de aprendizaje colaborativo en línea. Los resultados obtenidos muestran que los participantes en situaciones de pequeño grupo que requieren la elaboración de un producto escrito dedican una parte importante de su actividad discursiva a negociar la forma de organización de la actividad conjunta que van a adoptar y a asegurarse que todos la conocen. Por el contrario, la herramienta tecnológica utilizada en la situación colaborativa no parece tener impacto en el peso relativo del tipo de habla -relacionada con el contenido o con la actividad- de los participantes.
\end{abstract}

Palabras clave: actividad conjunta; influencia educativa; habla relacionada con la actividad; habla relacionada con el contenido; entornos CSCL-

\section{Introduction}

This paper looks at the articulation of two planes of discourse activity, or participants' talk, that form the basis of knowledge construction processes in online collaborative learning settings: those related to the organization of the joint activity and to the learning content. This choice of focus falls within the framework of investigations into Computer-Supported Collaborative Learning (CSCL) which, by analysing the content of the participants' discourse, seek to explain when, how and why interaction and communication exchanges inspire collaboration and encourage individual and collective learning. As Korschmann points out, these investigations share an interest in the "meaning and the practices of meaning-making in the context of joint activity" (2002, p. 20), while at the same time they stress the social, situated, reciprocal, dynamic nature of the collaborative learning processes (Stahl, 2006; Suthers, 2006) and draw attention to language as being the quintessential instrument for thinking, interthinking and learning with others (Mercer, 1995).

In the recent literature on CSCL that deals with the participants' discourse, there is a clear dichotomy between papers that focus on content-related talk - on-topic talk - and those that focus on other issues - off-topic talk. The former,

* Dirección para correspondencia [Correspondence address]: César Coll. Universitat de Barcelona. Departamento de Psicología Evolutiva de la Educación. P. Vall d'Hebron, 171. 08035 Barcelona. E-mail: ccoll@,ub.edu
Abstract: In the recent literature on CSCL which places the spotlight on participants' talk, there is a clear dichotomy between studies that focus on content-related talk and those that focus on off-topic or activity-related talk. In the approach adopted in this paper, based on the notion of educational influence, the guiding hypothesis is that both forms of talk are closely linked in the collaborative dynamics and that activity-related talk, far from being irrelevant, has an essential role to play in promoting the collaborative construction of knowledge. The paper empirically examines this hypothesis in four online collaborative learning situations. The results show that participants in small group situations requiring the preparation of a written product devote a major part of their discursive activity to negotiating the form of organization of their joint activity and to making sure that all members are familiar with it. In contrast, the technological tools used in the collaborative situation do not seem to have an impact on the relative weight of the type of participants' talk, either content-related or activity-related.

Key words: activity-related talk; CSCL settings; content-related talk; educational influence; joint activity.

which make up the bulk of these papers (see for example the reviews by De Wever, Schellens, Valcke, \& Van Keer, 2006; Dennen, 2008; Donnelly \& Gardner, 2009), argue that ontopic talk makes a direct contribution to the processes involved in learning (e.g. Guzdial \& Turns, 2000; Lipponen, Rahikainen, Lallimo, \& Hakkarainen, 2003; Veerman \& Veldhuis-Diermanse, 2001). This approach is shared by a great many other works which, while not explicitly identifying on-topic talk as their focus, use a number of analysis categories - elaborating and summarizing ideas or concepts, developing and exploring hypotheses, proposing new coconstructions on topics, defining terms and judging definitions, refining or elaborating already stated information, analysing arguments and applying new knowledge - which clearly correspond to this type of talk (see for example De Wever, van Winckle, \& Valcke, 2008; Garrison, Anderson, \& Archer, 2001; Gunawardena, Lowe, \& Anderson, 1997; Weinberger \& Fischer, 2006; Zhu, 2006).

However, in the corpus of data analysed in these works, along side communication exchanges dealing with learning content, another type of talk often appears. Some authors even note that talk dealing with content forms only a small part of the participants' talk (see for example the review by Rourke \& Kanuka, 2009). This other type of conversation off-topic talk - has typically been analysed from the perspective of its contribution to the establishment of an appropriate relational, affective-emotional atmosphere to support the collaborative learning processes and, in general, its contribution to social presence (e.g. Kreijns, Kirschner, \& Jochems, 
2003; Rourke, Anderson, Garrison, \& Archer, 2001; Swan, 2002; Tu \& McIsaac, 2002). Also, although to a lesser extent, some researchers have explored other dimensions of off-topic talk linked to motivational aspects, regulating or coordinating the collaborative work (e.g. Janssen, Erkens, Kanselaar, \& Jaspers, 2007; Järvelä \& Järvenoja, 2011; Meier, Spada, \& Rummel, 2007; Volet, Summers, \& Thurman, 2009).

So far the few works to analyse both types of talk in a single corpus of data (Akyol \& Garrison, 2008; de Laat, 2006; Lockhorst, Admiraal, \& Pilot, 2010; Paulus, 2009; Schellens \& Valcke, 2005; Strijbos, Martens, Jochems, \& Broers, 2004; Van der Pol, Admiraal, \& Simons, 2006; Veerman \& Veldhuis-Diermanse, 2001) make it clear that they both appear closely articulated in collaborative dynamics and that off-topic talk, far from being trivial or irrelevant, is essential for making collaborative knowledge construction on the learning content move forward. Of the variables that, according to these papers, may have the greatest impact on the participants' type of talk, they highlight the characteristics of the collaborative tasks, especially the degree to which they are structured (Lockhorst et al., 2010; Schellens \& Valcke, 2005; Strijbos et al., 2004), and the characteristics and affordances of the communication tools made available to the participants (Paulus, 2009; Van der Pol et al., 2006; Veerman \& Veldhuis-Diermanse, 2001). De Laat (2006) also points out that, in the course of resolving the learning tasks, participants develop various patterns of collaboration that differ from each other depending on which activities they contribute to most with their input; hence some participants have a high interest in contributing and discussing ideas, while others appear to concentrate more on managing the group's activity.

\section{Theoretical framework}

According to the approach taken in this paper, on-topic talk and off-topic talk are inseparable and should be studied together. The participants in a collaborative learning process should not be involved in a process of joint construction of meaning about the learning content alone, but also about the procedures they should follow to tackle it, about its requirements and characteristics, about the product or result, about the assumption and distribution of responsibilities that will enable this result to be achieved, and about the coordination of their activities. In other words collaborative learning situations are actually the scenario for a dual process of construction of meaning in which part of the process relates to learning content and part relates to the various aspects involved in how the joint activity is organized. Both processes are so closely interlinked that the ways in which participants organize, manage and regulate their joint activity have an effect on the meanings they construct, facilitating or hindering learning as the case may be.

This approach links directly to our previous papers studying the mechanisms of educational influence in formal and school education contexts in situations of face-to-face inter- action (Coll, 1990; 1999). Educational influence refers to the interpsychological processes by which teachers, and other educational agents should the case arise, help learners to construct progressively richer, more complex and more valid meanings about physical or symbolic situations, phenomena and objects. To fulfill its function and be effective, this help must be adapted to the construction of meaning process that the pupils are carrying out, which means it has to vary in type and degree depending on how the construction process progresses. However, as we have just mentioned, the construction of meaning process is dual-faceted; one facet relates to the organization of the joint activity and the other to the learning content, and so adjustments to the help provided and, in short, the mechanisms of educational influence likewise operate in this dual aspect.

However, in this respect there is a considerable difference between situations of guided knowledge construction (Mercer, 1995), which school teaching/learning situations would generally be, and the situations of collaborative knowledge construction that we are concerned with here, just as there is a difference between situations of face-to-face interaction and situations of online interaction. While the teacher is expected to be the main source of help and support for learning in situations of guided knowledge construction - without this having to mean that classmates cannot be, as they often are, an important source of educational influence -, in collaborative learning situations all the participants are potential sources of help for the other participants - without this having to mean a denial of the specific responsibility of the teacher. In this sense we talk of distributed educational influence (Coll, Bustos \& Engel, 2011; Coll, Engel \& Bustos, 2009) to refer to the fact that, in collaborative learning situations, not only can all the participants be potential sources of educational influence, the expectation is that they actually will be.

As regards situations of interaction based on communications that are written, asynchronous and without direct visual contact, as online collaborative learning activities usually are, the specificity lies in the fact that adopting a number of particular ways of organizing the joint activity and respecting the rules that govern them usually requires greater attention and effort from the participants. In order to collaboratively construct meanings about the learning content that are ever richer, more complex and more shared, participants have to agree about what they are going to do and how they are going to do it, plan who is going to do what and in what order, how they are going to coordinate their actions, what products or results they are going to generate, what requirements these products have to meet, and how they are going to make sure that the process develops according to plan. Unlike what happens in situations based on face-toface interaction, in this case the ways of organizing the joint activity are not usually immediately clear to the participants just because they have entered the setting. On the contrary, what normally happens is that the organization of the joint activity has to be explicitly formulated and a great deal of ef- 
fort needs to be devoted to ensuring that participants know the obligations and requirements that stem from it, and to identifying and re-agreeing any actions that do not satisfy these obligations and requirements, reminding people of them when necessary.

Taking these characteristics of collaborative learning situations in online settings into consideration led us to choose an approach to the study of educational influence that would take into account not only the help provided as regards the process of constructing meanings about the ways of organizing the joint activity, but also the help provided as regards the process of constructing meanings about the learning content. We therefore established three dimensions in the knowledge construction process in collaborative learning settings, identified respectively as management of social participation, management of the academic task and management of content (Coll, Bustos, Engel, de Gispert, \& Rochera, 2013). The first two involve meanings related to the organization of the joint activity, while the third involves those related to the learning content. It is also posited that both the development of the collaboration process and the results of the collaborative learning depend to a great extent on the expectation that the educational influence of the participants, taken as a whole, will cover these three dimensions.

Management of social participation refers to participants' talk in connection with establishing rules, instructions or orders about who can or must do what, how, when, with whom and how often. Management of the academic task refers to talk in connection with establishing rules, instructions and orders about what has to be done, how it has to be done, following what procedures, what end products have to be generated and what characteristics these products have to have. Both these dimensions, management of social participation and management of the academic task, are essential for analysing and understanding how participants organize their joint activity and set the context that makes it possible to construct and share meanings about the learning content. Indeed the third dimension concerns the management of content carried out by participants in this context of joint activity and refers to talk in direct connection with this content.

\section{Objectives}

Within the framework of this distinction between on-topic talk and off-topic talk and the theoretical approach described, the aim of this paper is to empirically examine the interrelation between content-related talk and activity-related talk in four online collaborative learning situations, compared with each other as regards the type of teaching and learning activity chat forum, small group work - and the technology tool used - Moodle forum, Knowledge Forum. To be exact, this general aim comprises the following specific objectives:

1. To formulate a proposal of categories for the analysis of the participants' contributions that will simultaneously take into account the participants' talk relating to the two dimensions involved in the joint activity's construction pro- cess - management of social participation and management of the academic task - and the participant's talk relating to the learning content - management of content.

2. To prove the viability of the proposal for analysis categories by applying it to participants' contributions in the four collaborative learning situations studied, and to assess its sensitivity in detecting differences between them as regards the weight of the talk relating to the three dimensions mentioned: management of social participation, management of the academic task and management of content.

3. To analyse the impact of the nature and characteristics of the teaching/learning activity - chat forum, small group work - and of the technology tool used - Moodle forum, Knowledge Forum - on the weight of the participants' talk relating to the three dimensions: management of social participation, management of the academic task and management of content.

4. To identify and describe profiles in participants' contributions based on the relative weight within them of talk concerning management of social participation, talk concerning management of the academic task and talk concerning management of content, and to analyse the possible impact of the nature and characteristics of the teaching/learning activity - chat forum, small group work - and of the technology tool used - Moodle forum, Knowledge Forum - on the frequency and distribution of these profiles.

\section{Method}

\section{Design}

Using case study methodology (Yin, 2003), we looked at four didactic sequences (DSs) ${ }^{2}$ from higher education that develop in natural contexts without the researchers' intervention. The four DSs chosen constitute a priori educational practices with sufficient elements of quality. As quality indicators we used students' replies to a questionnaire, completed by $70 \%$ of participants in the four cases, about how satisfied they were with the development of the DSs. Specifically, the students said that participating in the case had significantly enabled them to learn (average 3.85 on a 5 -point Likert scale) and gave themselves a substantially higher than average score (3.8 on a scale of 1 to 5 , with 1 being a fail and 5 excellent). It was also decided to select cases that differed as regards two criteria relevant to the investigation's objectives: the nature of the learning activities and the technology tool used (see Figure 1).

\footnotetext{
${ }^{2}$ A didactic sequence (DS) is defined as a process that includes all the typical components of a teaching and learning process - goals, content, teaching/learning activities and assessment activities - and in which it is
} possible to identify a beginning, a development and an end. 


\section{Type of teaching/learning activity}

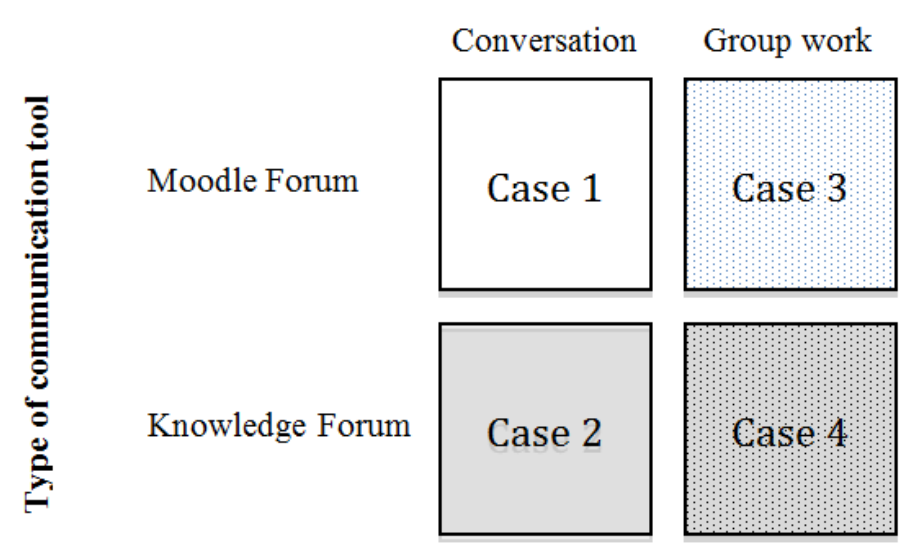

Figure 1. Features of selected cases.

The design therefore takes in two different types of activity: a chat forum, which is seen as a collaborative activity directed towards the comprehension and analysis of a specific subject, the aim of which is for students to obtain a rich, corroborated overall view of that subject; and an activity involving small group work directed towards the joint preparation of an open-ended written product. Both activities appear frequently in CSCL designs and correspond to two different types of pedagogic dialogue (Burbules, 1993). Typically in chat forums it is encouraged that contributions should be accepted and respected as manifestations of ideas, interpretations and different points of view regarding the subject under discussion; in collaborative group work, however, contributions are evaluated and accepted or not according to whether they enable the work to advance towards a preestablished common objective.

\section{Participants and context}

Cases 1 and 2 correspond to two complete DSs taught at the University of Barcelona in the academic year 2005-2006 as part of the psychology of education postgraduate syllabus. The teachers in both cases presented the task as a chat forum, pointing out that all contributions would be accepted as manifestations of ideas, interpretations and different points of view regarding the subject under discussion. Both teachers also explained that students were required to make a minimum of two contributions a week.

In Case 1 the participants - one teacher and 21 students (17 women and 4 men) - had 30 days in which to analyse and discuss the objectivity/subjectivity dilemma in psychoeducational research, using a Moodle platform forum to do so.

In Case 2 the participants - one teacher and 15 students (11 women and 4 men) - had 37 days in which to analyse and discuss the book Words and Minds (Mercer, 2000), using Knowledge Forum to do so.
Cases 3 and 4 correspond to two DSs taught at the National Autonomous University of Mexico in the academic year 2006-2007. In both cases the students, organized in small workgroups of between 4 and 6 members, had to resolve one task every week and, at the end of each week, hand in the corresponding written product. In both cases a oneweek training session was also provided on how to use the technology platform, but this is not the subject of analysis in this paper. Although different online settings were used, in both cases the small groups of students had a private space where only the teacher and group members could make contributions and read those made by other members of the same small workgroup.

In Case 3 one teacher and 28 students (all women), organized into six small workgroups, participated for 29 days in a seminar devoted to the drawing up of a teaching proposal based on case studies, as part of a subject on the psychology degree and using a Moodle forum for the purpose. The weekly tasks set by the teacher for the small groups to tackle collaboratively were: (i) the production of a conceptual map of the main concepts involved in teaching through the use of case studies; (ii) the construction of a case following the criteria proposed by Díaz Barriga (2006) and the formulation of discussion questions for it; (iii) the development of a pedagogic proposal in which general recommendations should be established following all the stages of case study methodology; and (iv) the presentation of the proposal itself and an assessment of those presented by the other small groups. This final task was developed in the classroom. The results we present in this paper correspond to two randomly-chosen small groups of five members each, and to the teacher's contributions directly relating to these groups of students as regards the resolution of the first three tasks set in the instructional process and developed online.

In Case 4 one teacher and 22 students (16 women and 6 men), organized into five small workgroups, participated for 28 days in a postgraduate seminar on teacher-training pro- 
cesses in classroom and virtual environments, using Knowledge Forum for the purpose. The weekly tasks set by the teacher for the small groups to tackle collaboratively were: (i) the production of a conceptual map of teaching competencies and a conceptual map of assessment rubrics; (ii) the definition of a teacher-training scenario; (iii) the identification and delimitation of the teaching competencies to be assessed in the scenario defined; and (iv) the construction of an assessment rubric for those teaching competencies. The results we present in this paper correspond to the contributions from two randomly-chosen small groups of four and five members respectively, and to the teacher's contributions directly relating to these groups of students.

\section{Data collection}

The main corpus of data collected corresponds to the record of contributions and documents supplied by the teachers and students in the various different work and communication spaces used during the development of the DSs. Table 1 shows the number of messages and documents provided by the participants in each case.
Table 1. Total contributions and documents presented and analysed in the four DSs.

\begin{tabular}{cccc}
\hline & & Total contributions & Total documents \\
\hline Case 1 & & 211 & 7 \\
Case 2 & & 302 & 0 \\
Case 3 & group 1 & 195 & 79 \\
& group 2 & 143 & 54 \\
Case 4 & group 1 & 872 & 148 \\
& group 2 & 313 & 54 \\
total & & 2036 & 342 \\
\hline
\end{tabular}

Other information was also collected (interviews and self-reports from the teachers, course materials, self-reports and questionnaires from the students) and used to provide contextual elements and so help in understanding and interpreting the results.

\section{Data analysis}

In line with the study's objectives, the analysis focused on identifying contributions or fragments of contributions corresponding to the three dimensions defined: management of meanings relating to social participation, management of meanings relating to the academic task, and management of meanings relating to learning content.

Table 2. Categories and examples of the management of social participation.

\begin{tabular}{lc}
\hline \multicolumn{1}{c}{ Description } & Code \\
\hline Formulation or reminder of the rules of participa- & P_fr \\
tion or action for participants. &
\end{tabular}

Request or requirement for clarification of the rules of participation or action for participants.

Formulation of clarification of the rules of participation or action for participants, by request of other participants.

Proposal for revision or reformulation of the rules of participation or action for participants.

Evaluation of the rules of participation or action for participants or of the proposals for rules of participation or action for participants: positive (agreement, relevance, interest...), negative (disagreement, degree of requirement...), expression of doubts or confusion.

Evaluation of the extent to which the rules of participation or action for participants are followed: positive (evidence of respect or compliance), negative (evidence of lack of respect or noncompliance).
Principle of participative balance: if the product has to be collective, participation must tend towards balance. This is not new, but we followed the line of "minimum intervention" and no maximum limit. What I would now say is that we need to be alert while we participate, making sure everybody is doing it (I know it is difficult); that the silences speak volumes. [teacher, case 2]

P_fp The "format" of interaction is new, for me at least, and I'm not too clear about procedures like 'how long do you wait for your next turn?', 'how do we decide to go on to the next point in the debate?'... [student, case 1]

P_pp Try not to open so many lines of discussion - only when you really need to - and read all the messages from your group and from me. (in the group forum and the news forum). [teacher, case 3]

P_pr Supporting Maria ${ }^{1}$ and Veronica would be more dynamic and useful - if we're aiming to share and construct together - we should be more concise and explicit. [student, case 1]

P_vr Luisa, as I've already said to other teams, the work forum is perfectly sufficient for working on the product for block 1. Other teams have proved it, they're on the point of finishing their map, working on reciprocal interaction exclusively through the forum without using the chat even once. [teacher, case 3]

P_vc Please, everyone, because I think we've got a good few activities and the work could be shared out more fairly, I'd like not to have to feel the absence of some of the team members. [student, case 4]

\footnotetext{
${ }^{1}$ In order to protect people's identities, the participants' names have been changed.
} 
Table 3. Categories and examples of the management of academic task.

\begin{tabular}{|c|c|c|}
\hline Description & Code & Example \\
\hline $\begin{array}{l}\text { Formulation or reminder of the characteristics or } \\
\text { requirements of the task, how to tackle it, and its } \\
\text { product or result. }\end{array}$ & T_fr & $\begin{array}{l}\text { I think that to make it easier we should be outlining the competencies for } \\
\text { all the material we have and justifying the outline or competency we pro- } \\
\text { pose, and then it will be easier for Juan to put them all together and, as the } \\
\text { teacher says, not get carried away with it all. [student, case 4] }\end{array}$ \\
\hline $\begin{array}{l}\text { Request or requirement for clarification about the } \\
\text { characteristics or requirements of the task, how to } \\
\text { tackle it, and its product or result as regards both } \\
\text { its initial version and any possible proposals for re- } \\
\text { formulation. }\end{array}$ & T_fp & $\begin{array}{l}\text { The first thing I want to know is whether what we're meant to be doing or } \\
\text { the aim of the forum is to look at the subject of "objectivism and subjec- } \\
\text { tivism" on a conceptual analysis level of "epistemological problem" or at a } \\
\text { level of "methodological problem", i.e. at a level where theories of quanti- } \\
\text { tative or qualitative methodology tackle the subject. [student, case 1] }\end{array}$ \\
\hline $\begin{array}{l}\text { Request or requirement for clarification about the } \\
\text { characteristics or requirements of the task, how to } \\
\text { tackle it, and its product or result, by request of }\end{array}$ & $T_{-p p}$ & $\begin{array}{l}\text { It's obvious that the discussion has to have an epistemological level and an } \\
\text { applicational, methodological level. I think we should start with the first } \\
\text { but without completely forgetting the second. [teacher, case 1] }\end{array}$ \\
\hline
\end{tabular}
other participants.

Proposal for revision or reformulation of the char- T_pr acteristics or requirements of the task, how to tackle it, and its product or result

Evaluation of the task characteristics or require- T_ve ments, how to tackle it, and its product or result as regards both its initial version and any possible reformulations: positive (agreement, relevance, interest...), negative (disagreement, degree of requirement...), expression of doubts or confusion. Evaluation of the degree of respect for or fulfill- T_vc ment of the requirements of the task, how to tackle it, and its product or result: positive (evidence of respect or compliance) or negative (evidence of lack of respect or non-compliance).

A week before the end of the forum, I think we should work on a very specific task to enable us to arrive at some sort of shared conclusion (even if it's only a very limited part). [student, case 1]

I think what Manuel proposed is interesting, that we base the competency we contribute not just on an article or document, but on the product handed in last week, which is the teaching scenario. That's our guide for proposing competencies. [student, case 4]

Despite this I really believe that we're doing a good job because we're managing to construct shared meanings (through written language in this case, and that's not bad at all). [student, case 1]

Table 4. Categories and examples of the management of content.

$\frac{\text { Table 4. Categories and examples of the management of content. }}{\text { Description Code }}$

Contribution on own initiative of own meanings, C_sp presented as own with a certain degree of preparation (development, enlargement, details).

Contribution on own initiative of meanings at- C_rf tributed to external sources or reference to one or more sources of meanings, with a certain degree of preparation (development, enlargement, details). Contribution of meanings via attached documents C_doc written by self or other.

Literal or almost literal reminder of meanings pre- C_re viously presented by other participants.

Request for other participants to contribute mean- C_rq ings about a topic or to comment on meanings contributed by whoever formulates the request.

Reply to a request from another participant to contribute meanings about a topic or to comment on meanings contributed by whoever formulated the request. Example
Obviously it has to be considered that thanks to discussing the case in the
subject group chosen, relevant topics are looked at (as far as I can see it
would be "Special Education" and the topic "Educational Integration")
and relevant content learnt. After the dilemma come the characters and
then the narrative gets structured. [student, case 3]
Perrenoud works out the figure of the ideal teacher based on a dual record
of citizenship and construction of competencies. [student, case 4]

And on the same subject, I'd like to include an article on qualitative research that seems to me to specifically provide a general view of the subject. I hope you find it useful for getting to grips with the key ideas we've been discussing! [student, case 1]

As far as the study questions are concerned, the question "What should Carlos's parents do, take him out of school and keep him at home even though this decision may affect his development? Why?" I feel suggests an answer, even if it doesn't completely fit the discussion. [student, case 3]

With all that's been said, I'm still not clear about it. What exactly are the mechanisms that enable us to interthink? What happens not only in the conversation exchange, in the subject, to enable us to understand or try to understand the reference framework and the content of its speaker?. [student, case 2]

C_rrq It seems to me, Luisa Fernanda, that the question you propose of the psychological mechanisms involved in the "interthinking" is a very interesting issue and one that we should formulate as we move forward in the book. For now, in chapter 3 - the given and the new - there is a series of strategies, techniques to enable us to understand the links in meaning between the new and the given (recapitulation, reformulation...). Mercer also talks about "cohesive resources" (like repetition and anaphoric reference) as techniques for establishing a "connected meaning" in the course of the 
Favourable assessment (signs of agreement and C_vf acceptance) of meanings previously contributed by other participants.

Critical assessment (signs of fairly formal and C_vc forceful disagreement or difference) of meanings previously contributed by other participants.

Identification of topics or subjects for attention, C_it further study and discussion.

Request to another participant for details, clarifica- C_pp tion or explanations about meanings they previously presented.

Reply to a request for details, clarification or ex- C_rpp planations from another participant about meanings previously presented by the person replying. comprehension process (spoken or written). [student, case 2, replying to a previous contribution]

The case is well outlined, the characters are valid and their attitudes are believable. [teacher, case 3]

But (there's always a but in this life) you still need to polish the work, give it a more precise focus for this scenario, argue more about occupational training teachers and the teaching they give, their needs and the problems involved in teacher training. OK? [teacher, case 4]

According to the scenario given and to one of the main problems facing occupational training teachers, I suggest we evaluate two groups of competencies, last week's product. Which ones? Types of teaching and the teacher's teaching methodology. The other group would be the assessment group. [student, case 4]

But I don't see how we can approach the question methodologically if we don't agree at an epistemological level about the need to revise the rules, concepts and tools. Can you explain your idea a bit more? [student, case 1] For me the biggest problem isn't the positioning in an epistemological option, but rather the availability of a methodological infrastructure. We can obviously go much more deeply into the conceptualization of an epistemological option focused on the subjective, i.e. that involves an emic-type approach to the subject studied. However, I think we would quickly agree that this option is possible and can be scientific (objective), with the way of understanding these terms that the option implies, a question that has been discussed a little in this forum. [student, case 1, replying to a previous contribution]

Identification and/or correction of errors, incom- C_ie prehension or omissions (real or not) in the meanings previously contributed by others or by self.

Expression or signs of doubt, unanswered ques- C_ed tions, incomprehension or uncertainty about one or more of the topics that are being discussed.

Formulation of synopses, summaries or recapitula- C_si tions including meanings previously contributed by self and by other participants.
No, remember that it isn't a case in itself (like those that appear in the files of an institution). What has to be developed is a controversial case that involves a dilemma and can generate a discussion with at least two possible solutions or standpoints. [teacher, case 3]

Well, I still have the feeling we're not moving ahead (maybe this is the objective or I just don't understand enough), we still have the need and interest to look for the approach to objectivity with subjectivity in order to find out what we think is subjective about human knowledge, with observable and quantifiable measurements. I keep coming up against a brick wall. Am I the only one that feels like that? [student, case 1]

And then my summary (including my interpretation) of the readings I sent them, which have to be tested against the scenario and the competencies we noted, in order to establish the rubric: Trends in teaching odontology have moved from a disciplinary approach (by subject) and from a master (explanatory) class (teaching) to an approach based on competencies and focusing on the students' learning. [student, case 4]
We have used the fragment as a coding unit. A fragment is a part of a contribution (message or contribution in a document) that can be interpreted and coded into one of the categories of the analysis system established (see Tables 2, 3 and 4). A contribution can be formed of one or various fragments. Identifying and coding fragments was carried out separately for each of the three dimensions, which means that both the number of fragments coded and their delimitation can be, and indeed often are, different in each of the three dimensions. Fragments of one contribution can therefore be coded into other dimensions if necessary. However, the categories of each dimension are exclusive, so one particular fragment can only be coded into one category in each dimension. Thus in our analysis of the results presented below, when one particular contribution contains various fragments coded in the same category of a dimension, they are counted only once.
Given the dialogic nature of the categories defined, in order to classify the fragments of contributions it is essential to organize the participants' contributions without changing their sequence in time or the references that the participants themselves made to contributions previously made by other participants.

To satisfy the criteria of reliability and consistency required when analysing content, a combination of qualitative and quantitative procedures were applied in this study. The members of the research team, organized in pairs, applied an agreed protocol for analysing the three dimensions of the content analysis, which had previously been reviewed and established in accordance with the characteristics of the situations observed. The pairs of analysts met periodically - with $25 \%, 50 \%, 75 \%$ and $100 \%$ of the data coded - in order to check the coding, thereby making it possible to carry out an iterative process moving to and fro between the data and 
their interpretation (Chi, 1997; Schrire, 2006), renegotiating and eventually redefining the criteria for applying categories. Differences between coders were resolved by discussion until agreement was reached. In cases of unresolved disagreement, the participation of a third independent judge was requested. Once the process was finished, the reliability of all the fragments was identified and their coding calculated, resulting in Kappa indices of over $90 \%$ in all cases.

\section{Results}

We present the results organized into three sections. The first is devoted to the results of the analysis carried out on the content of participants' contributions in the four cases and in the three dimensions of educational influence considered: management of social participation, management of the academic task and management of content. The second shows the results of the analysis carried out on the categories of each of the three dimensions to which participants contributed with their input. Finally, the third shows the results of the analysis of how far each participant contributes to the management of the three dimensions of educational influence. The first two sets of results apply to objectives 2 and 3 , aimed respectively at confirming the viability of the proposal for analysis categories and its sensitivity in distinguishing between the cases analysed, and at assessing the impact of the nature and characteristics of the teaching/learning activity chat forum or small group work - and the technology tool used - Moodle forum or Knowledge Forum - on the weight of the participants' talk relating to the three dimensions. The third set of results concerns objective 4 , aimed at identifying profiles in the participants' contributions according to the relative weight within them of the three types of talk - talk relating to social participation, to management of the academic task and to management of content - and at assessing the impact of the nature and characteristics of the teaching/learning activity and of the technology tool on the frequency and distribution of the profiles identified.

\section{Results of the analysis carried out on the content of participants' contributions in the four cases and in the three dimensions of educational influence (par- ticipation, task, content)}

Table 5 shows the frequencies and percentages of the participants' contributions corresponding to the three dimensions of educational influence in the four cases. Table 6 presents the values that result from applying Pearson's chisquared test to the distributions of the participants' contributions between the three dimensions in the four cases. Looking at these tables enables us to make five assertions relevant to objectives 2 and 3 of our study.

Table 5. Frequencies and percentages of contributions in the three dimensions of educational influence in the four cases.

\begin{tabular}{|c|c|c|c|c|c|c|c|c|c|c|c|c|}
\hline & \multirow{2}{*}{\multicolumn{2}{|c|}{ Case 1}} & \multirow{2}{*}{\multicolumn{2}{|c|}{ Case 2}} & \multicolumn{4}{|c|}{ Case 3} & \multicolumn{4}{|c|}{ Case 4} \\
\hline & & & & & \multicolumn{2}{|c|}{ group 1} & \multicolumn{2}{|c|}{ group 2} & \multicolumn{2}{|c|}{ group 1} & \multicolumn{2}{|c|}{ group 2} \\
\hline & $\mathrm{f}$ & $\%$ & $\mathrm{f}$ & $\%$ & $\mathrm{f}$ & $\%$ & $\mathrm{f}$ & $\%$ & $\mathrm{f}$ & $\%$ & $\mathrm{f}$ & $\%$ \\
\hline Social participation & 43 & 7.13 & 34 & 5.39 & 47 & 8.97 & 54 & 13.47 & 336 & 25.00 & 170 & 27.55 \\
\hline Academic task & 89 & 14.76 & 86 & 13.63 & 153 & 29.20 & 103 & 25.69 & 358 & 26.64 & 130 & 21.07 \\
\hline Content & 471 & 78.11 & 511 & 80.98 & 324 & 61.83 & 244 & 60.85 & 650 & 48.36 & 317 & 51.38 \\
\hline Total & 603 & 100 & 631 & 100 & 524 & 100 & 401 & 100 & 1344 & 100 & 617 & 100 \\
\hline
\end{tabular}

Table 6. Values obtained by applying Pearson's chi-squared test to the distributions of contributions in the three dimensions of educational influence in the four cases.

\begin{tabular}{|c|c|c|c|c|c|c|c|}
\hline & \multirow{2}{*}{$\begin{array}{c}\text { case } \\
1\end{array}$} & \multirow{2}{*}{$\begin{array}{c}\text { case } \\
2\end{array}$} & \multicolumn{2}{|c|}{ case 3} & \multicolumn{2}{|c|}{ case 4} \\
\hline & & & & group 1 & group 2 & group 1 & group 2 \\
\hline & ase 1 & - & .350 & $.001 *$ & $.001^{*}$ & $.001 *$ & $.001^{*}$ \\
\hline & ase 2 & - & - & $.001 *$ & $.001 *$ & $.001 *$ & $.001 *$ \\
\hline case & group 1 & - & - & - & .072 & $.001 *$ & $.001 *$ \\
\hline 3 & group 2 & - & - & - & - & $.001 *$ & $.001 *$ \\
\hline case & group 1 & - & - & - & - & - & .027 \\
\hline 4 & group 2 & - & - & - & - & - & - \\
\hline
\end{tabular}

First, in all the cases and groups studied we find participants' contributions associated with all three dimensions of talk belonging to the analysis model based on the concept of educational influence.

Second, in all the cases and groups analysed, participants' contributions are mainly situated within talk relating to learning content: $78 \%$ of total contributions from all participants in Case 1, 81\% in Case 2, around 60\% in Case 3 and around $50 \%$ in Case 4 . There are substantially fewer contributions focusing on social participation and the academic task in all cases and groups.

Third, when students have to collaboratively prepare written products in small groups (Cases 3 and 4), the weight of talk about social participation and the academic task is greater than in collaborative learning tasks in which this does not need to be done, when the discussion itself is considered to be the product of the learning activity (Cases 1 and 2).

Fourth, as shown in Table 6, the participants' contributions in the three dimensions have a different distribution in the four cases, with the differences observed being statistically significant except on three occasions: when comparing Cases 1 and 2 (both organized around a discussion forum learning activity) and the two groups in Case 3 and the two groups in Case 4.

Fifth, the results are inconclusive as regards the impact of the nature and characteristics of the technology tool Moodle forum, Knowledge Forum - on the distribution of the participants' talk relating to the three dimensions. In fact, as we have already mentioned, there is no significant difference between the two cases organized around a discussion forum 
activity (Case 1: Moodle forum; Case 2: Knowledge Forum). However, there is a difference between the two cases organized as small group work for the preparation of a written product (Case 3: Moodle forum; Case 4: Knowledge Forum).

Results of the detailed analysis of participants' contributions in the four cases based on the categories (Table 2) of the three dimensions of educational influence

Tables 7, 8 and 9 show the frequency and percentage of the participants' contributions coded into the different categories of the social participation, academic task and content dimensions in the four cases. Table 10 presents the values that result from applying Pearson's chi-squared test to the distributions of these contributions.

As far as contributions relating to management of social participation are concerned, there are two categories, "formulation or reminder of the rules of participation" (P_fr) and "evaluation of the extent to which they are followed" (P_vc), which appear with high or moderately high percentages in all cases and groups, although there are big differences between them. The one exception is Case 2, in which the percentage is substantially lower. We also see a moderately high percentage for the category "evaluation of the rules of participation (P_vr)", but only in Cases 1 and 2.

Table 7. Frequencies and percentages of contributions in the dimension of social participation in the four cases.

\begin{tabular}{|c|c|c|c|c|c|c|c|c|c|c|c|c|}
\hline & \multirow{2}{*}{\multicolumn{2}{|c|}{ Case 1}} & \multirow{2}{*}{\multicolumn{2}{|c|}{ Case 2}} & \multicolumn{4}{|c|}{ Case 3} & \multicolumn{4}{|c|}{ Case 4} \\
\hline & & & & & \multicolumn{2}{|c|}{ group 1} & \multicolumn{2}{|c|}{ group 2} & \multicolumn{2}{|c|}{ group 1} & \multicolumn{2}{|c|}{ group 2} \\
\hline & $\mathrm{f}$ & $\%$ & $\mathrm{f}$ & $\%$ & $\mathrm{f}$ & $\%$ & $\mathrm{f}$ & $\%$ & $\mathrm{f}$ & $\%$ & $\mathrm{f}$ & $\%$ \\
\hline P_fr & 12 & 27.91 & 3 & 8.82 & 19 & 40.43 & 24 & 44.44 & 119 & 35.42 & 84 & 49.41 \\
\hline P_fp & 1 & 2.33 & 2 & 5.88 & 0 & 0.00 & 2 & 3.70 & 20 & 5.95 & 6 & 3.53 \\
\hline P_pp & 3 & 6.98 & 2 & 5.88 & 2 & 4.26 & 3 & 5.56 & 16 & 4.76 & 11 & 6.47 \\
\hline P_pr & 4 & 9.30 & 2 & 5.88 & 0 & 0.00 & 0 & 0.00 & 0 & 0.00 & 1 & 0.59 \\
\hline P_vr & 13 & 30.23 & 13 & 38.24 & 1 & 2.13 & 1 & 1.85 & 20 & 5.95 & 2 & 1.18 \\
\hline P_vc & 10 & 23.26 & 12 & 35.29 & 25 & 53.19 & 24 & 44.44 & 161 & 47.92 & 66 & 38.82 \\
\hline Total & 43 & 100 & 34 & 100 & 47 & 100 & 54 & 100 & 336 & 100 & 170 & 100 \\
\hline
\end{tabular}

Table 8. Frequencies and percentages of contributions in the dimension of academic task in the four cases.

\begin{tabular}{|c|c|c|c|c|c|c|c|c|c|c|c|c|}
\hline & \multirow{2}{*}{\multicolumn{2}{|c|}{ Case 1}} & \multirow{2}{*}{\multicolumn{2}{|c|}{ Case 2}} & \multicolumn{4}{|c|}{ Case 3} & \multicolumn{4}{|c|}{ Case 4} \\
\hline & & & & & \multicolumn{2}{|c|}{ group 1} & \multicolumn{2}{|c|}{ group 2} & \multicolumn{2}{|c|}{ group 1} & \multicolumn{2}{|c|}{ group 2} \\
\hline & $\mathrm{f}$ & $\%$ & $\mathrm{f}$ & $\%$ & $\mathrm{f}$ & $\%$ & $\mathrm{f}$ & $\%$ & $\mathrm{f}$ & $\%$ & $\mathrm{f}$ & $\%$ \\
\hline$T_{-f r}$ & 12 & 13.48 & 25 & 29.07 & 65 & 42.48 & 46 & 44.66 & 156 & 43.58 & 62 & 47.69 \\
\hline$T_{-f p}$ & 8 & 8.99 & 2 & 2.33 & 16 & 10.46 & 4 & 3.88 & 31 & 8.66 & 7 & 5.38 \\
\hline T_pp & 14 & 15.73 & 3 & 3.49 & 23 & 15.03 & 14 & 13.59 & 45 & 12.57 & 15 & 11.54 \\
\hline T_pr & 15 & 16.85 & 6 & 6.98 & 0 & 0.00 & 0 & 0.00 & 0 & 0.00 & 2 & 1.54 \\
\hline T_ve & 21 & 23.60 & 20 & 23.26 & 10 & 6.54 & 6 & 5.83 & 44 & 12.29 & 4 & 3.08 \\
\hline$T_{-v c}$ & 19 & 21.35 & 30 & 34.88 & 39 & 25.49 & 33 & 32.04 & 82 & 22.91 & 40 & 30.77 \\
\hline Total & 89 & 100 & 86 & 100 & 153 & 100 & 103 & 100 & 358 & 100 & 130 & 100 \\
\hline
\end{tabular}

Table 9. Frequencies and percentages of contributions in the dimension of teaching/learning content in the four cases.

\begin{tabular}{|c|c|c|c|c|c|c|c|c|c|c|c|c|}
\hline & \multirow{2}{*}{\multicolumn{2}{|c|}{ Case 1}} & \multirow{2}{*}{\multicolumn{2}{|c|}{ Case 2}} & \multicolumn{4}{|c|}{ Case 3} & \multicolumn{4}{|c|}{ Case 4} \\
\hline & & & & & \multicolumn{2}{|c|}{ group 1} & \multicolumn{2}{|c|}{ group 2} & \multicolumn{2}{|c|}{ group 1} & \multicolumn{2}{|c|}{ group 2} \\
\hline & $\mathrm{f}$ & $\%$ & $\mathrm{f}$ & $\%$ & $\mathrm{f}$ & $\%$ & $\mathrm{f}$ & $\%$ & $\mathrm{f}$ & $\%$ & $\mathrm{f}$ & $\%$ \\
\hline C_sp & 115 & 24.42 & 146 & 28.57 & 62 & 19.14 & 46 & 18.85 & 169 & 26.00 & 58 & 18.30 \\
\hline C_rf & 59 & 12.53 & 105 & 20.55 & 16 & 4.94 & 16 & 6.56 & 49 & 7.54 & 44 & 13.88 \\
\hline C_doc & 7 & 1.49 & 0 & 0.00 & 79 & 24.38 & 54 & 22.13 & 148 & 22.77 & 54 & 17.03 \\
\hline C_re & 45 & 9.55 & 5 & 0.98 & 4 & 1.23 & 2 & 0.82 & 15 & 2.31 & 3 & 0.95 \\
\hline C_rq & 51 & 10.83 & 46 & 9.00 & 32 & 9.88 & 32 & 13.11 & 77 & 11.85 & 74 & 23.34 \\
\hline C_rrq & 21 & 4.46 & 42 & 8.22 & 17 & 5.25 & 18 & 7.38 & 53 & 8.15 & 11 & 3.47 \\
\hline C_pp & 20 & 4.25 & 9 & 1.76 & 4 & 1.23 & 2 & 0.82 & 10 & 1.54 & 3 & 0.95 \\
\hline C_rpp & 15 & 3.18 & 7 & 1.37 & 6 & 1.85 & 1 & 0.41 & 4 & 0.62 & 1 & 0.32 \\
\hline C_vf & 90 & 19.11 & 116 & 22.70 & 27 & 8.33 & 40 & 16.39 & 64 & 9.85 & 39 & 12.30 \\
\hline$C_{-}$vc & 22 & 4.67 & 19 & 3.72 & 61 & 18.83 & 23 & 9.43 & 36 & 5.54 & 19 & 5.99 \\
\hline C_ie & 3 & 0.64 & 7 & 1.37 & 13 & 4.01 & 6 & 2.46 & 15 & 2.31 & 1 & 0.32 \\
\hline C_it & 12 & 2.55 & 6 & 1.17 & 0 & 0.00 & 4 & 1.64 & 5 & 0.77 & 1 & 0.32 \\
\hline C_si & 6 & 1.27 & 3 & 0.59 & 3 & 0.93 & 0 & 0.00 & 3 & 0.46 & 8 & 2.52 \\
\hline C_ed & 5 & 1.06 & 0 & 0.00 & 0 & 0.00 & 0 & 0.00 & 2 & 0.31 & 1 & 0.32 \\
\hline Total & 471 & 100 & 511 & 100 & 324 & 100 & 244 & 100 & 650 & 100 & 317 & 100 \\
\hline
\end{tabular}


Table 10. Values obtained by applying Pearson's chi-squared test to the distributions of categories in the three dimensions in the four cases.

\begin{tabular}{|c|c|c|c|c|c|c|c|c|}
\hline \multirow[b]{2}{*}{ Dimension } & \multirow[b]{2}{*}{ cases } & \multirow[b]{2}{*}{ groups } & \multirow{2}{*}{ case 1} & \multirow{2}{*}{ case 2} & \multicolumn{2}{|c|}{ case 3} & \multicolumn{2}{|c|}{ case 4} \\
\hline & & & & & group 1 & group 2 & group 1 & group 2 \\
\hline \multirow{6}{*}{$\begin{array}{l}\text { Social participa- } \\
\text { tion }\end{array}$} & \multicolumn{2}{|c|}{ case 1} & - & .325 & $.001 *$ & $.001 *$ & $.001 *$ & $.001 *$ \\
\hline & \multicolumn{2}{|c|}{ case 2} & - & - & $.001 *$ & $.001 *$ & $.001 *$ & $.001 *$ \\
\hline & \multirow{2}{*}{ case 3} & group 1 & - & - & - & .676 & .349 & .426 \\
\hline & & group 2 & - & - & - & - & .544 & .959 \\
\hline & \multirow{2}{*}{ case 4} & group 1 & - & - & - & - & - & .004 \\
\hline & & group 2 & - & - & - & - & - & - \\
\hline \multirow{6}{*}{ Academic task } & case 1 & & & $.001 *$ & $.001 *$ & $.001 *$ & $.001 *$ & $.001 *$ \\
\hline & case 2 & & - & & $.001 *$ & $.001 *$ & $.001 *$ & $.001 *$ \\
\hline & \multirow{2}{*}{ case 3} & group 1 & - & - & - & .337 & .336 & .154 \\
\hline & & group 2 & - & - & - & - & .083 & .668 \\
\hline & \multirow{2}{*}{ case 4} & group 1 & - & - & - & - & - & .003 \\
\hline & & group 2 & - & - & - & - & - & - \\
\hline \multirow{6}{*}{ Content } & case 1 & & - & $.001 *$ & $.001 *$ & $.001 *$ & $.001 *$ & $.001 *$ \\
\hline & case 2 & & - & - & $.001 *$ & $.001 *$ & $.001 *$ & $.001 *$ \\
\hline & \multirow{2}{*}{ case 3} & group 1 & - & - & - & .286 & $.001 *$ & $.001 *$ \\
\hline & & group 2 & - & - & - & - & $.001 *$ & $.001 *$ \\
\hline & \multirow{2}{*}{ case 4} & group 1 & - & - & - & - & - & $.001 *$ \\
\hline & & group 2 & - & - & - & - & - & - \\
\hline
\end{tabular}

In the dimension corresponding to the academic task we again find two categories, "formulation or reminder of the characteristics or requirements of the task, the way to tackle it and its product or result" (T_fr) and "evaluation of the extent to which the task requirements were respected or met" (T_vc), which again appear with high or moderately high percentages in all cases and groups, although with considerable differences. The differences in other categories, however, are even more marked. The category "evaluation of task characteristics or requirements" ( $T_{-}$ve) shows a moderately high percentage in Cases 1 and 2 and Group 1 of Case 4, but not in Groups 1 and 2 of Case 3 or Group 2 of Case 4. Something similar happens with the category "request or requirement for clarification about the characteristics or requirements of the task, how to tackle it and its result " (T_pp), which shows moderately high percentages in Case 1 and the two groups of Cases 3 and 4, but not in Case 2 .

Finally, in the dimension relating to the learning content, which is where the greatest number of participants' contributions in the four cases are concentrated, the distribution of the categories appears to be more complex. First of all there is a high or moderately high percentage of inputs in categories relating to the contribution of ideas or points of view: "contribution of own meanings" (C_sp), "contribution of meanings attributed to external sources" (C_rf) and "contribution of meanings via documents" (C_doc). The differences between cases and groups are large, however. While the first category (C_sp) appears with sizeable percentages in all cases and groups, the second (C_rf) does so much more unevenly, and the third (C-doc) only has a relatively high percentage in Cases 3 and 4 and is virtually absent from Cases 1 and 2. Secondly, attention should be drawn to the percentage of contributions in the category "favourable assessment of meanings previously contributed by other participants" (C_vf) in Cases 1 and 2, Group 2 of Case 3 and to a lesser extent Groups 1 and 2 of Case 4, especially when compared to the contributions coded as critical assessments (C_vc) in the same cases and groups, which are much less frequent. The exception is Group 1 of Case 3, where critical assessments are appreciably higher than favourable ones. And thirdly, there are noticeably low percentages of contributions in some categories that are particularly relevant in the processes of negotiating meanings involved in collaborative work and learning: "identification of topics or subjects for attention" (C_it), "identification and/or correction of errors" (C_ie) and "formulation of synopses, summaries or recapitulations" (C_si).

The results of applying Pearson's chi-squared test (see Table 10) show the impact of the nature and characteristics of the teaching/learning activity on the distribution of the categories corresponding to the dimensions of social participation and academic task. In fact the values in the table indicate that the differences are not significant when the distributions for Cases 1 and 2 or the groups in Cases 3 and 4 are compared. However, they are significant in comparisons between Case 1 or Case 2 on the one hand and the groups of Cases 3 and 4 on the other. Something similar happens with the distribution of the categories corresponding to the dimension relating to content, the difference being that in this case all the comparisons indicate that the distributions differ significantly except when Group 1 is compared with Group 2 in Case 3.

As regards the impact of the nature and characteristics of the technology tool on the distribution of the categories of the three dimensions, the results are again fairly inconclusive. There is no significant difference in the distributions of the categories corresponding to social participation and academic task between the two cases organized around a discussion forum activity (Case 1: Moodle forum; Case 2: Knowledge Forum), nor between the two cases organized as small group 
work tasked with preparing a written product (Case 3: Moodle forum; Case 4: Knowledge Forum). However, when the distributions of the categories corresponding to content are analysed, all comparisons show significant differences with one exception, that involving the distributions of Groups 1 and 2 of Case 3.

Caution should be taken when interpreting the results of this part of the analysis because, due to the small size of the sample and the high number of categories, we find a number of boxes with frequencies lower than 5 at a rate of over $20 \%$ in some distributions, especially in the dimension relating to social participation, which calls into question the statistical significance of the differences found.

Results of the analysis of the extent to which participants in the four cases contribute to management of the three dimensions of educational influence

With the aim of assessing the participants' input to the management of the three dimensions, we first counted the number of dimensions to which each participant contributes.
Table 11 shows the number and percentage of participants who contribute to three, two and one dimensions in each case and group. All the participants in the two DSs organized around collaborative learning activities involving small group work (Cases 3 and 4) contribute to all three dimensions. However, in the two DSs organized around discussion activities, only half the participants in Case $1(11 / 22)$ and just over half in Case $2(9 / 16)$ contribute to all three dimensions. The other participants contribute to two dimensions (10/21 and 4/16 respectively) or even just one (1/22 and $3 / 16$ respectively). In all cases and groups the teacher always contributes to all three dimensions. All the students who contribute to just one dimension always do so regarding content. When they contribute to two dimensions, one always relates to content and the other usually relates to the academic task (of the 10 students that contribute to two dimensions in Case 1, 7 do not contribute to management of social participation and 3 do not contribute to management of the academic task; of the 4 students that contribute to two dimensions in Case 2, none contributes to management of social participation).

Table 11. Numbers and percentages of participants who contribute to three, two and one dimensions in the four cases.

\begin{tabular}{|c|c|c|c|c|c|c|c|}
\hline & & \multicolumn{2}{|c|}{3 dimensions } & \multicolumn{2}{|c|}{2 dimensions } & \multicolumn{2}{|c|}{1 dimensions } \\
\hline & & $\mathrm{f}$ & $\%$ & $\mathrm{f}$ & $\%$ & $\mathrm{f}$ & $\%$ \\
\hline case $1(n=22)$ & & 11 & 50.00 & 10 & 45.45 & 1 & 4.55 \\
\hline case $2(n=16)$ & & 9 & 56.25 & 4 & 25.00 & 3 & 18.75 \\
\hline & group $1(n=6)$ & 6 & 100.00 & 0 & 0.00 & 0 & 0.00 \\
\hline case 3 & group $2(n=6)$ & 6 & 100.00 & 0 & 0.00 & 0 & 0.00 \\
\hline & group $1(n=6)$ & 6 & 100.00 & 0 & 0.00 & 0 & 0.00 \\
\hline case 4 & group $2(n=5)$ & 5 & 100.00 & 0 & 0.00 & 0 & 0.00 \\
\hline
\end{tabular}

We then identified different participant profiles according to the relative weight carried by talk connected to management of social participation, management of the academic task and management of content in their contributions. To this end we began by eliminating participants who contribute little or very little to the joint activity. Participation in a collaborative process is expected to be equitably distributed. Thus in a group with 10 participants, for example, the participation would be completely balanced if each of them contributed $10 \%$ of the inputs. Consequently we considered that a participant makes a relevant contribution to the joint activity when they contribute at least $50 \%$ of the inputs that would correspond to them if the participation were completely balanced. Once the participants who contribute little or very little to the development of the joint activity had been eliminated via this process (see Table 12), we defined three different types of profile designated complete, mixed and simple depending on the relative weight of their contribution to management of the three dimensions. We say that a profile is complete when the participant makes a relevant contribution to the management of all three dimensions. The simple profile is used when the participant makes a relevant contribution to just one dimension, and hence this profile can take three forms: simple profile in social participation, simple profile in academic task or simple profile in learning content. Finally, we say the profile is mixed when the participant makes a relevant contribution to two dimensions, and therefore this profile can also take three forms: mixed social participation-academic task, mixed social participationcontent or mixed academic task-content.

The procedure adopted to identify the profiles was as follows. When a participant makes more than the average number of contributions for their group in one dimension and contributes less than $25 \%$ of the inputs to each of the other dimensions, we considered them to have a simple profile in the first dimension. When a participant is above the average for their group in two dimensions and in the third contributes $25 \%$ or more of the inputs, we considered their profile to be complete: social participation-academic tasklearning content. However, if the participant contributes less than $25 \%$ of the inputs in the third dimension, this would be a mixed profile.

Table 12 shows the frequencies and percentages of the participants' profiles - and of those participants that were not given a profile due to their scant contribution to the joint activity - in the four cases. Overall, the most frequent profiles are simple (for content) and complete. Second is the mixed academic task-content profile, and third the mixed so- 
cial participation-content profile. No participants presented a simple profile in social participation or academic task, or a mixed profile in social participation-academic task. In Cases 1 and $2-$ DSs organized around discussion forum learning activities - the simple profile in content is more frequent, in contrast to Cases 3 and 4 - DSs organized around learning activities involving small group work - in which one of the most frequent profiles is the complete, except in Group 2 of Case 4 , in which the mixed profile in social participationcontent appears more. The fact that in Table 12 there is a very high percentage of boxes with frequencies of less than 5 makes it unfeasible to calculate the statistical significance of the differences found.

Table 12. Frequencies and percentages of participants' profiles in the four cases.

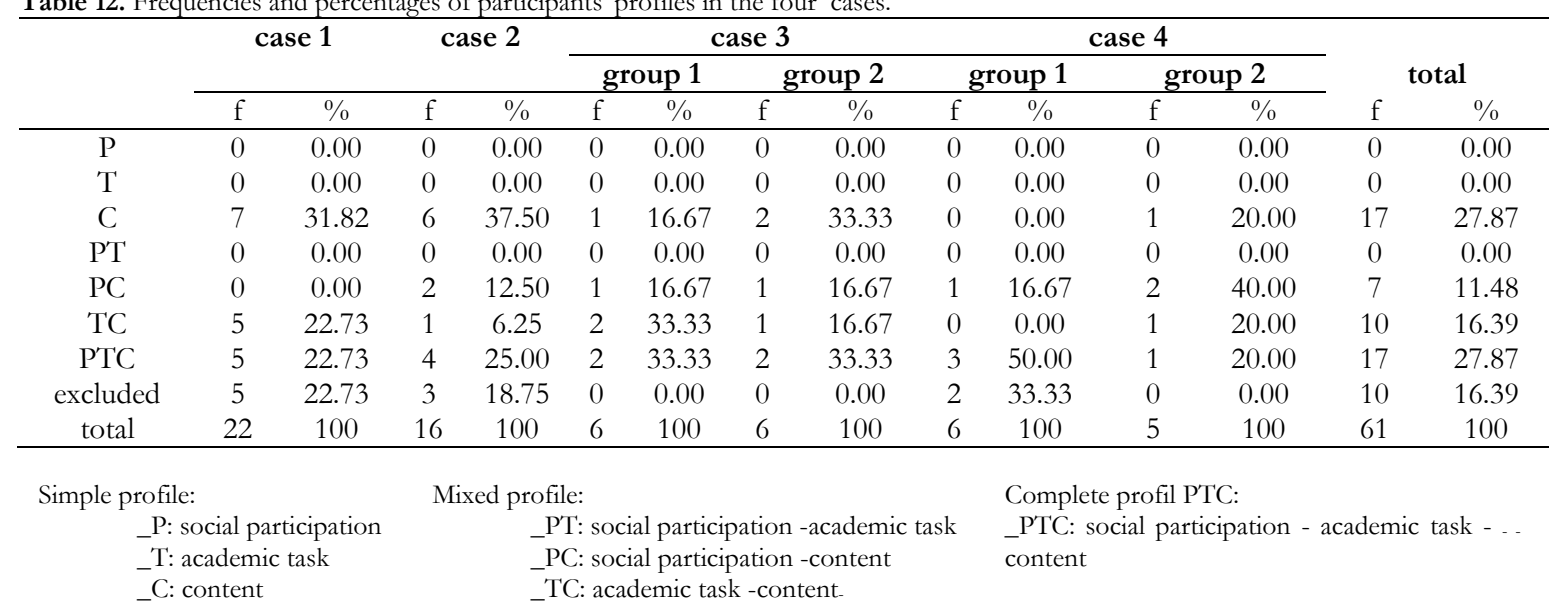

\section{Discussion and conclusions}

As regards the first two objectives set, the results obtained enable us to conclude that analysing the content of the conversations of participants in CSCL situations is not only essential for understanding how participants introduce, negotiate and confirm meanings about the learning content, but also for understanding how they agree on what to do jointly and how to carry it out. Our proposal for analysis categories based on the idea of distributed educational influence has enabled us to empirically test the interrelation between the participants' content-related talk - management of content and activity-related talk - management of social participation and management of the academic task. The results also highlight the high presence of this second type of talk in the four situations studied. These results give more support to the need stressed in previous papers (Akyol \& Garrison, 2008; de Laat, 2006; Lockhorst, Admiraal, \& Pilot, 2010; Paulus, 2009; Schellens \& Valcke, 2005; Van der Pol, Admiraal, \& Simons, 2006; Veerman \& Veldhuis-Diermanse 2001) to take into account both types of talk in order to obtain a more complete image of the collaborative dynamic established in CSCL settings.

As far as the third objective is concerned, first of all our results coincide with previous papers (Lockhorst et al., 2010; Strijbos et al., 2004) in the sense that the nature and characteristics of the learning activities have a great impact on the participants' type of talk. Indeed their talk varies appreciably in the cases we have studied depending on whether we are dealing with DSs organized around small group work and learning activities that entail the preparation of a final prod- uct or with DSs organized around chat forums on a particular topic. In the first case, participants need to agree to a greater extent about what they are going to do and how they are going to do it, plan who is going to do what and in what order, how they are going to coordinate their actions, what products or results they are going to generate, what requirements these products have to meet, and how they are going to ensure that the process develops according to plan. In other words they need to explicitly formulate which way of organizing the joint activity they are going to adopt, devote more effort to ensuring that everyone knows the rules and requirements that derive from it, identify and correct any actions that fall outside the expected, and remind people of actions where necessary. Indeed we see from our data that in small group situations that involve the preparation of a written product, participants devote almost $20 \%$ more of their contributions to managing social participation and the academic task than they do in situations organized around chat forums.

Secondly, we found no direct correspondence between the characteristics and affordances of the communication tools given to the participants to use - Moodle forum, Knowledge Forum - and the type of talk they become involved in, as has been found in a number of previous papers on the subject (Van der Pol, Admiraal, \& Simons, 2006; Veerman \& Veldhuis-Diermanse, 2001). As in the study by Paulus (2009), in the cases we have looked at the use of one tool or another does not seem to alter the frequency or the articulation between talk related to organization of the joint activity and talk related to learning content. 
As regards the fourth objective, we managed to identify different profiles for the exercise of educational influence among participants according to their discourse activity. To identify these profiles we took into account what participants contribute with their input to the management of social participation, the management of the academic task and the management of content, and to what extent they contribute, both as regards the total of their own inputs and those made by the group as a whole in each dimension. Thus we have been able to identify three different categories of profile in the cases studied: i) the complete profile, in which the relative weight of the talk is relevant in all three dimensions of the joint activity (social participation-academic task-content); ii) the mixed profile, in which the relevant weight of the talk is relevant in two of the three dimensions of the joint activity (social participation-academic task, social participationcontent or academic task-content); and iii) the simple profile, in which the relative weight of the talk is relevant in just one dimension (social participation, academic task or content). The results obtained suggest that the talk differs in degree and type between participants. Hence the most repeated profiles were, in first place, the simple profile in content management and the complete profile; in second place, the mixed profile in academic task and content; and in third place, the mixed profile in social participation and content. Meanwhile the simple profiles in social participation or academic task and the mixed profile in social participation and academic task did not appear in any of the cases studied. These results represent an advance along the lines suggested by certain authors, like de Laat (2006), when they say that participants in collaborative processes tend to develop their own different patterns of action. The analysis carried out has enabled us to establish that the frequency and distribution of the profiles identified is characteristic and idiosyncratic of each of the cases considered, while no clear indicators have been obtained of a direct relation between that frequency and distribution and the nature and characteristics of the learning activity or the type of forum used.

Our work clearly shows that participants in CSCL situations should pay attention not only to the learning content but also to the characteristics and requirements of the task and the social organization required to tackle it. It also shows that participants assume to different degrees and in different ways their responsibility for making the collaborative knowledge construction process move forward. From a theoretical perspective both aspects are equally relevant for understanding how and why certain collaborative processes may or may not be effective. They also provide some interesting indications for the practical side. On the one hand

\section{References}

Akyol, Z., \& Garrison, R. (2008). The Development Of A Community Of Inquiry Over Time In An Online Course: Understanding The Progression And Integration Of Social, Cognitive and Teaching Presence. Journal of Asynchronous Learning Networks, 12 (3-4), 3-22.

Burbules, N. C. (1993). Dialogue in teaching: theory and practice. New York: they point to the importance of including specific help in CSCL situations for the two activity planes that are the basis of knowledge construction processes in online collaborative learning settings: those related to the organization of the joint activity and those related to the learning content. And on the other hand they suggest that, beyond the particular characteristics of the discourse activity of each separate participant, what really counts in these situations is that the group as a whole guarantees the appropriate management of the three main aspects or dimensions involved in the exercise of educational influence: social participation, academic task and content.

To conclude, it must be acknowledged that this paper is a first approach and has a number of serious limitations. Apart from those already noted in the results presentation that derive from the low number of cases studied and the small sample sizes, and those associated with the communication tools and the learning activities around which the DSs were organized, we would like to highlight three limitations that in our opinion are especially relevant both from a theoretical point of view and because of their practical implications. The first is the need to study how the participants' discourse activity evolves in the course of the DSs and the activities that comprise them with the aim of analysing the time effects in the different types of talk (Akyol \& Garrison, 2008) and their effect on the development and quality of the collaborative knowledge construction processes. Secondly, our results provide no information about whether or not the participants' discourse activity advances their learning and to what extent. This shows that there is a need for future studies to look more deeply into the extent to which possible advances, setbacks and achievements in the forms of organization of the participants' joint activity are related to advances, setbacks and achievements in their learning processes and results. Thirdly and lastly, our analysis does not deal with the socio-affective dimension of the collaborative process, which is undoubtedly essential for understanding how the participants' joint activity is organized. Our analysis reveals that the emotional and affective aspects of learning are not a topic of conversation for the participants, beyond the conventional greetings and farewells of online etiquette in these means of communication. As van der Pol, Admiraal, \& Simons (2006) have pointed out, these aspects do not necessarily need to manifest themselves explicitly, although intuitively they are reflected in many of the participants' contributions. Tackling them, however, calls for a type of analytical approach different from the one presented here and which we hope we will be able to develop in future papers.
Teachers College, Columbia University [El diálogo en la enseñanza. Teoría y práctica. Buenos Aires: Amorrortu editores].

Chi, M. T. H. (1997). Quantifying Qualitative Analyses of Verbal Data: A Practical Guide. The Journal of the Learning Sciences, 6 (3), 271-315.

Coll, C. (1990). Un marco psicológico de referencia para la educación esco- 
lar: la concepción constructivista del aprendizaje y la enseñanza. En C. Coll, J. Palacios y A. Marchesi (Comps.), Desarrollo psicológico y educación. II. Psicología de la educación (pp. 435-453). Madrid: Alianza.

Coll, C. (1999). La concepción constructivista como instrumento para el análisis de las prácticas educativas escolares. En C. Coll (Coord.), Psicología de la Instrucción: la enseñanza y el aprendizaje en la educación secundaria (pp. 16-44). Barcelona: Horsori.

Coll, C., Bustos, A., \& Engel, A. (2011). Perfiles de participación y presencia docente distribuida en redes asíncronas de aprendizaje: la articulación del análisis estructural y de contenido. Revista de Educación, 354, 657688.

Coll, C., Bustos, A., Engel, A., de Gispert, I., \& Rochera, M. J. (2013). Distributed Educational Influence and Computer-Supported Collaborative Learning. Digital Education Review, 24, 23-42.Consultado el 12-05-2014 en http://greav.ub.edu/der/index.php/der

Coll, C., Engel, A., \& Bustos, A. (2009). Distributed Teaching Presence and Participants' Activity Profiles: A theoretical approach to the structural analysis of Asynchronous Learning Networks. European Journal of Education, 44 (4), 521-538. Retrieved (29/06/2013) from http://onlinelibrary.wiley.com/doi/10.1111/j.14653435.2009.01406.x/full

De Laat, M. F. (2006). Networked Learning. Apeldoorn: Politie Academic

De Wever, B., Schellens, T., Valcke, M., \& Van Keer, H. (2006). Content analysis schemes to analyze transcripts of online asynchronous discussion groups: A review. Computers \& Education, 46 (1), 6-28.

De Wever, B., van Winckle, M., \& Valcke, M. (2008). Discussing Patient Management Online: The Impact of Roles on Knowledge Construction for Students Interning at the Paediatric Ward. Advances in Health Sciences Education, 13, 25-42.

Dennen, V. F. (2008). Looking for evidence of learning: Assessment and analysis methods for online discourse. Computers in Human Behavior, 24 (2), 205-219.

Díaz Barriga, F (2006). Enseñanza situada: vínculo entre la escuela y la vida. México, DF: McGraw-Hill Interamericana.

Donnelly, R., \& Gardner, J. (2009). Content analysis of computer conferencing transcripts. Journal of Interactive Learning Environments, 20 (4), 469485.

Garrison, D. R., Anderson, T., \& Archer, W. (2001). Critical thinking, cognitive presence and computer conferencing in distance education. American Journal of Distance Education, 15 (1), 7-23.

Gunawardena, C. N., Lowe, C. A., \& Anderson, T. (1997). Analysis of global online debate and the development of an interaction analysis model for examining social construction of knowledge in computer conferencing. Journal of Educational Computing Research, 17 (4), 397-431.

Guzdial, M., \& Turns, J. (2000). Effective discussion through a computermediated anchored forum. The Journal of the Learning Sciences, 9, 437-470.

Janssen, J., Erkens, G., Kanselaar, G., \& Jaspers, J. (2007). Visualization of participation: Does it contribute to successful computer-supported collaborative learning? Computers \& Education, 49, 1037-1065.

Järvelä, S., \& Järvenoja, H. (2011). Socially constructed self-regulated learning and motivation regulation in collaborative learning groups. Teachers College Record, 113 (2), 350-374.

Koschmann, T. (2002). Dewey's contribution to the foundations of CSCL research. In G. Stahl (Ed.), Proceedings of CSCL 2002: Foundations for a CSCL community (pp. 17-22). Mahwah, NJ: Lawrence Erlbaum Associates.

Kreijns, K., Kirschner, P. A., \& Jochems, W. (2003). Identifying the pitfalls for social interaction in computer-supported collaborative learning environments: A review of the research. Computers in Human Behavior, 19, 335-353.

Lipponen, L., Rahikainen, M., Lallimo, J., \& Hakkarainen, K. (2003). Patterns of participation and discourse in elementary students' computer- supported collaborative learning. Learning and Instruction, 13 (5), 487509

Lockhorst, D., Admiraal, W., \& Pilot, A. (2010). CSCL in teacher training: what learning tasks lead to collaboration? Technology, Pedagogy and Education, 19 (1), 63-78.

Meier, A., Spada, H., \& Rummel, N. (2007). A rating scheme for assessing collaboration quality. International Journal of Computer-Supported Collaborative Learning, 1, 63-86.

Mercer, N. (1995). The guided construction of knowledge: Talk amongst teachers and learners. Clevedon: Multilingual Matters.

Mercer, N. (2000). Words and Minds: how we use language to think together. London: Routledge.

Paulus, T. M. (2009). Online but off-topic: negotiating common ground in small learning groups. Instructional Science, 37, 227-245.

Rourke, L., \& Kanuka, H. (2009) Learning in Communities of Inquiry: A Review of the Literature. Journal of Distance Education, 23 (1), 19-48.

Rourke, L., Anderson, T., Garrison, R., \& Archer, W. (2001). Assessing social presence in asynchronous text-based computer conferencing. Journal of Distance Education, 14 (2).

Schellens, T. \& Valcke, M. (2005). Collaborative learning in asynchronous discussion groups: What about the impact on cognitive processing? Computers in Human Behavior, 21, 957-975.

Schrire, S. (2006). Knowledge building in asynchronous discussion groups: Going beyond quantitative analysis, Computers \& Education, 46 (1), 4970

Stahl, G. (2006). Group cognition. Computer Support for Building Collaborative Knowledge. Cambridge, MA: MIT Press.

Strijbos, J. W., Martens, R. L., Jochems, W. M. G., \& Broers, N. J. (2004). The effect of functional roles on group efficiency: Using multilevel modelling and content analysis to investigate computer-supported collaboration in small groups. Small Group Research, 35, 195-229.

Suthers, D. D. (2006). Technology affordances for intersubjective meaning making: A research agenda for CSCL. International Journal of ComputerSupported Collaborative Learning, 1 (3), 315-337.

Swan, K. (2002). Immediacy, social presence, and asynchronous discussion. In J. Bourne, \& J. C. Moore (Eds.). Elements of Quality Online Education, Volume 3. Needham, MA: Sloan Center for Online Education.

Tu, C. H., \& McIsaac, M. (2002). The relationship of social presence and interaction in online classes. The American Journal of Distance Education, 16 (3), 131-150.

Van der Pol, J., Admiraal, W., \& Simons, P. R. J. (2006). The affordance of anchored discussion for the collaborative processing of academic texts. International Journal Computer-Supported Collaborative Learning, 1, 339-357.

Veerman, A., \& Veldhuis-Diermanse, E. (2001). Collaborative learning through computer mediated communication in academic education. In P. Dillenbourg, A. Eurelings, \& K. Hakkarainen (Eds.), European perspectives on computer-supported collaborative learning. Proceedings of the First European Conference on CSCL (pp. 625-632). Maastricht, Netherlands: University of Maastricht Press.

Volet, S., Summers, M., \& Thurman, J. (2009). High-level co-regulation in collaborative learning: How does it emerge and how is it sustained? Learning and Instruction, 19, 128-143.

Weinberger, A., \& Fischer, F. (2006). A framework to analyze argumentative knowledge construction in computer-supported collaborative learning. Computers \& Education, 46, 71-95.

Yin, R. K. (2003). Case study research: Design and methods (3rd ed.). London: Sage Publications.

Zhu, E. (2006). Interaction and cognitive engagement: An analysis of four asynchronous online discussions. Instructional Science, 34, 451-480.

(Article received: 22-5-2014; revision received: 15-6-2014; accepted: 20-6-2014) 